\title{
Teaching Reform in higher Vocational Colleges under the New Media Environment
}

\author{
Hongcai Li, Changyong Lin, Yonghua Xuan, Hong Xu \\ Department of Medicine, Binzhou Polytechnic College, Binzhou, 256600, Shandong, China \\ Email: 252418973@qq.com
}

Keywords: new media; higher vocational colleges; education and teaching; reform

\begin{abstract}
With the coming of information society, new media application in the society is more and more widely. In the new era, the demand for the ability of the students is getting higher and higher, and many higher vocational colleges also started the education teaching reform to enhance students' comprehensive quality. Based on this, this article expound on the characteristics of new media related, then analyzes the new media's influence on education in higher vocational colleges teaching, explores the new media environment under the path of the education teaching reform in higher vocational colleges, in order to promote the development of higher vocational colleges teaching, promote the improvement of students' comprehensive ability.
\end{abstract}

\section{Introduction}

The arrival of the new media era has a great impact on the politics, economy and education of the whole society. As a technical college that trains professional and technical talents for the country, higher vocational colleges are under the influence of the new media environment. In order to train more high-quality talents, we will constantly adjust their education and teaching mode in order to meet the needs of social development and meet the trend of social development.

\section{The Characteristics of the New Media}

At this stage, with the rapid development of information technology, new media, such as QQ, WeChat, microblog and so on, begin to appear. New media is supported by network information technology, with the aid of the timeliness and rapidity of the network, a network platform for the dissemination of real-time messages to the public, with the following characteristics:

\subsection{Immediacy}

Fast transmission is a major advantage of new media. Users can receive the latest news through mobile phone, computer or other intelligent terminals in the shortest time, which really breaks the time and space limitation of traditional media. Compared with the traditional media, the news information of the new media can be released in the first time, no longer bound by the cycle and deadline. In recent years, with the explosion of hot news, users can receive hot news anytime and anywhere through the network. In addition, through the network, hot news can also be broadcast live, especially for natural disasters and traffic accidents. Through new media, users can learn about the accident site in the first place, the situation, and then carry out an active rescue. This is much shorter and faster than traditional media such as television and newspapers, and helps to reduce the damage caused by accidents.

\subsection{Interactive}

Compared with the traditional media, the new media has a strong interactivity. Traditional TV, radio and other media can only let people passively receive information, but cannot make the masses communicate. The new media has unique advantages in this respect. The information transmission of the new media is bidirectional, and the user can choose to block the information content that he does not like, can actively and selectively receive the information content that he is 
interested in. At the same time, the users can also use the platforms such as micro-blog to express their views on a certain issue. In short, in a new media environment, people can be both producers of information, also be the dissemination of information. The new media has created an interactive platform for people in the new era.

\subsection{The Mass of Network Information}

New media is the product of information network society and the most important form of media development in the new period. Different from traditional newspapers and TV media, new media can carry massive information resources, from astronomy to geography. Users can use mobile phones, mobile television, computers, tablets and other network terminals to understand mass information, accept new media mass information services [1].

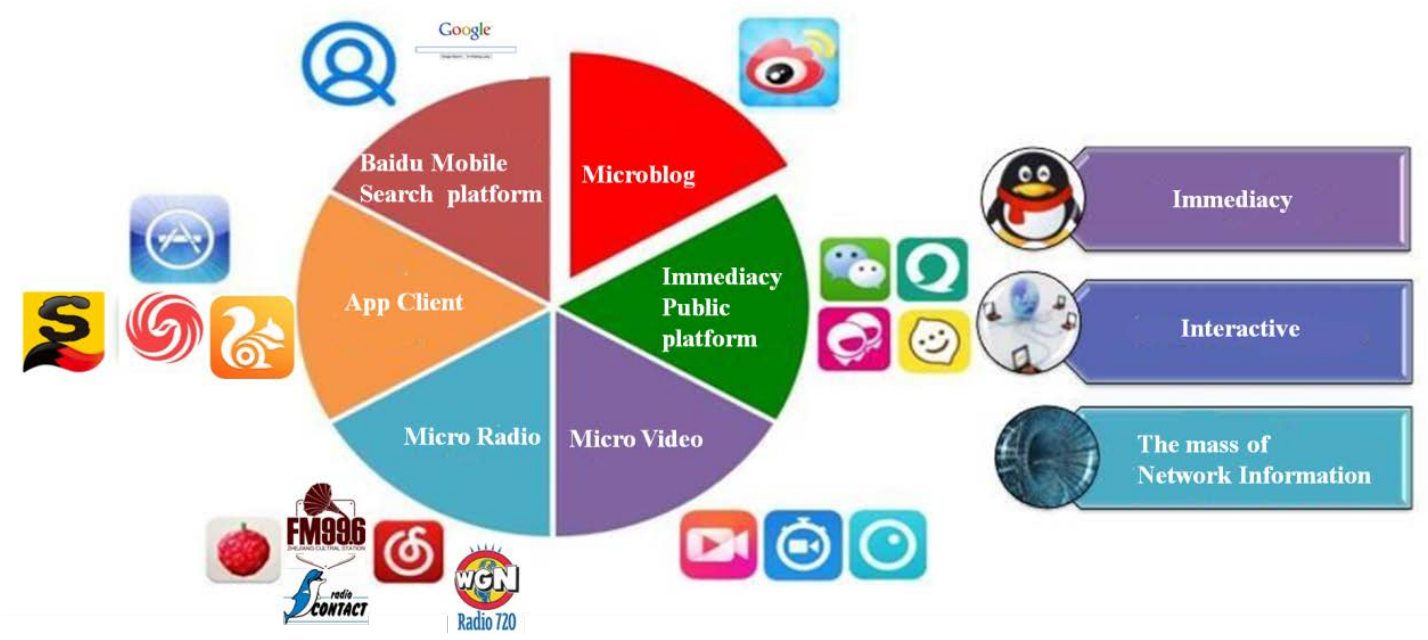

Fig. 1 The forms and characteristics of the new media

To sum up, we can understand that new media has the characteristics of immediacy, interactivity and magnanimity (Fig. 1), which accelerates the process of social development to a large extent, and is of great significance to the social development of our country. The new media environment has put forward new requirements for the students' ability in the new period. Therefore, higher vocational colleges should actively carry out the reform of educational and teaching mode in order to contribute to the cultivation of high-quality talents.

\section{The New Media's Impact on Education Teaching in Higher Vocational Colleges}

\subsection{Pushing the Higher Vocational College Education Teaching Way and Student Study Way of Change}

At present, with the rapid development of information technology, new media equipment has been widely used in the society, which has promoted the change of teaching methods in higher vocational colleges. The teaching methods of higher vocational colleges in the new period are often presented in the form of new media. In order to make students accept professional knowledge quickly and improve their learning ability, the mixed learning, flipping class, microlecture and MOOC are adopted to carry out vocational teaching in the new period [2].

In the new era, the number of new media users is more young students. The popularity of new media equipment has greatly changed the way students read and learn. The new media is mainly in the form of pictures and videos, so students in the new media environment will mainly read and study in the form of "see", which reduces the reading of paper books. In addition, according to the characteristics of real-time, interactivity and mass information of new media, students can make a study plan suitable for their own development, and make full use of the advantages of new media to complete their learning tasks and expand their knowledge. Therefore, the new media environment also promotes the change of students' learning style. 


\subsection{Putting forward Higher Requirements for the Teaching Ability of Higher Vocational Teachers}

Although new media can bring mass information resources to the public, but these mass information resources communicators include both professionals and ordinary people. The cultural level of information communicators is very different, for students who are eager to explore, it is difficult to distinguish the available value of information and identify active and effective information. Without the professional guidance of teachers, it is easy to introduce students into social misunderstanding, and then bring great influence to their outlook on life and values [3].

In addition, the widespread use of new media has increased student inertia to a certain extent. The emergence of "homework help" and "Little Apes search" software has led students to start the web as soon as they encounter problems. Even the bad phenomenon of direct plagiarism has seriously reduced the quality of the students' homework and affected the students' learning level. Therefore, teachers should keep pace with the times, master the use and use of new media tools in the new era, understand relevant information in advance, help students quickly identify effective information, and achieve an effective combination of new media and classroom teaching, carry out classroom transformation and upgrading. At the same time, in the new media environment, students' desire for knowledge is stronger, which puts forward higher requirements for school administrators and teachers [4].

\subsection{Promoting the Progress of Teachers' Educational Idea and Teaching Technology}

The promotion of new media can make teachers quickly understand the new trends of international education and teaching development, keep up with the pace of education and teaching development, constantly update the educational concept. In higher vocational education, appropriate micro-courses, flipping classrooms and online and offline mixing classroom teaching form improve its ability to use new media. Through the way of classroom teaching, students' interest in learning can be improved better, and students' active learning can be promoted, thus the quality of classroom teaching can be improved. In addition, under the new media environment, many higher vocational colleges begin to use cloud computing technology to analyze students' learning rules and behaviors through cloud learning analysis technology. The auxiliary teaching in the school is of great help.

\section{The Path of Educational and Teaching Reform in Higher Vocational Colleges under the New Media Environment}

\subsection{Exploring Various Teaching models with the Help of New Media Technology}

Under the new situation of promoting new media technology in an all-round way, higher vocational colleges should make full use of this form, introduce new media technology, and integrate new media technology into teaching in the new period, showing multi-media teaching materials and individualized teaching. In addition, schools should also conduct training for teachers on the new information media teaching methods, such as mixed learning, micro-lessons, and flipping classes, so that teachers can understand the characteristics and functions of new media, choose appropriate teaching methods for their own courses, and carry out practical research in their own classroom.

For example, like some mechanical design courses in higher vocational colleges, teachers can use 3D aided design software for classroom teaching. Through 3D three-dimensional form, they can create different visual feelings for students. In the design of mechanical parts, it is very difficult for a student to complete the three-dimensional space design of a component if only by simple imagination. If he uses 3D aided design software, it is easy to do so. Teachers can let students use 3D aided design software. It is of great significance for the improvement of teaching efficiency to show their initial conception through a three-dimensional form to make students feel their design effect intuitively. Therefore, in the teaching of higher vocational education, under the influence of new media technology, teachers should choose the new media teaching methods which match the 
subject of teaching according to the characteristics of their own courses, and explore the diversified teaching design which makes the students welcome.

\subsection{Creating Individualized Learning Platform with the Help of New Media}

In recent years, with the diversification of the form of running higher vocational colleges in our country, there are more and more students, including not only ordinary high school graduates, but also secondary vocational students, corporate personnel, as well as students who study technology from undergraduate to higher vocational colleges. The diversity of students has put forward higher requirements on the level of education and teaching in Higher Vocational Colleges in China. Therefore, higher vocational colleges should make full use of multimedia technology to create individualized learning platform, aiming at different learning levels of students from different sources of students, to let students fully grasp the advantages of the platform, according to their actual learning needs, choose the appropriate learning content. The learning situation is monitored and tracked effectively, so as to help the students to study independently and cooperatively, and to promote the students' learning efficiency.

\subsection{Renewing Teachers' Teaching Ideas and Improving Teachers' Ability to Apply New Media Technologies}

In the new era, with the extensive application and popularization of new media technology, as far as teachers in higher vocational education are concerned, they should renew their ideas, change their traditional teaching methods and be good at teaching with new media technology. It should recognize the advantage of new media technology to students, understand the high efficiency of new media technology teaching, and improve its ability to carry new media technology through school training and social learning. In the new period, teachers should take the students as the main body and turn themselves into the promoters of learning. Under the new media environment, teachers should guide students to study independently, help students to identify effective information and bad information, and promote the development of learning. Students are more effective in learning [5].

\section{Conclusion}

In summary, according to the characteristics of the new media and the influence of the new media on the education and teaching of higher vocational colleges, the article analyzes and discusses the educational and teaching reform in higher vocational colleges under the new media environment. The expression and display of the knowledge points in new media teaching is an intuitive, image, real and specific innovation model. Its application has been gradually recognized and grasped by the teachers in higher education institutions. Through the new media teaching, students can deepen their understanding, thinking, and even instant communication on the knowledge system, effectively solving practical problems, and further stimulate interest in learning. New media teaching has broken the barriers of traditional teaching methods and is becoming a new vane. This article hopes to play an effective reference.

\section{Acknowledgement:}

In this paper, the research was sponsored by the Vocational Teaching Reform of Shandong Province (Research on the teaching design of MOOC in the Vocational Colleges, Project No. 2015095).

\section{References}

[1] Xin Tan. Education and Teaching Reform in higher Vocational Colleges under the New Media Environment [J]. Education and careers, 2016 (16): 49-51.

[2] Mingqing Feng, Feng Yudong, Yuan Shuai. Research on Teaching Reform of higher Vocational 
Education under Internet Environment [J]. Education and Teaching Forum, 2016 (15): 101-102.

[3] Shuangcai Li. The influence of New Media on Teaching Reform in higher Vocational Colleges [J]. Business, 2015 (17): 230.

[4] Zhiwei Chen. On the Teaching Reform of Mental Health of higher Vocational College students under the New Media Environment [J]. Higher Education Journal, 2016 (18): 135-136.

[5] Yanning Cao. The influence and Strategy of New Media Environment on ideological and political Education of higher Vocational College students [D]. Suzhou University, 2010. 